\title{
The Structure of Ceroptene
}

\author{
MARTIN NILSSON \\ Organisk-kemiska Institutionen, Kungl. Tekniska Högskolan, Stockholm, Sweden
}

\begin{abstract}
Ceroptene, the yellow pigment of Pityrogramma triangularis, has been reinvestigated. The evidence of degradation and synthesis indicates that it is a methyl enol ether of 2-cinnamoyl-6,6-dimethylcyclohexane-1,3-5-trione (II), either 5-methoxy-2-cinnamoyl-6,6-dimethylcyclohex-4-ene-1,3-dione (IV) or less probably 3-methoxy-2-cinnamoyl6,6-dimethylcyclohex-3-ene-1,5-dione (VI).
\end{abstract}

n the fronds of many ferns of the family Pteridaceae*, and especially on those belonging to the genus Pityrogramma, there is a white or yellow secretion on the dorsal surfaces, and these ferns are therefore sometimes cultivated for decorative purposes. In botanical literature the coating is often described as a wax layer ("ceraceous ferns"), but investigations by Blasdale ${ }^{2}$ and by Zopf ${ }^{3}$ at the beginning of this century show that it contains appreciable amounts of enolic compounds.

The "golden-back fern", Pityrogramma triangularis, Kaulf. (earlier known as Gymnogramme triangularis and due to some confusion in literature also as Ceropteris triangularis), was investigated by Blasdale, who isolated a crystalline, yellow pigment, m.p. $135^{\circ}$, for which he proposed the name ceroptene. He described it as an acidic compound, which analysed for $\mathrm{C}_{18} \mathrm{H}_{18} \mathrm{O}_{4}$ and gave benzoic acid on oxidation. On treatment of ceroptene with hydroiodic acid he obtained a product, m.p. $182^{\circ}\left(\mathrm{C}_{11} \mathrm{H}_{11} \mathrm{IO}_{3}\right.$ ?), which also gave benzoic acid on oxidation, but only ill-defined products on treatment with alkali. Blasdale did not propose any structure for the pigment and no further work on ceroptene appears to have been reported since.

Ceroptene has now been reinvestigated. Fronds of $P$. triangularis were extracted with ether, the extract was freed from lipid material, and eventually the yellow pigment was obtained in fair yield from the alkali-soluble fraction. It melted somewhat unsharply at $137-140^{\circ}$ and the analytical data agreed with the composition proposed by Blasdale $\left(\mathrm{C}_{18} \mathrm{H}_{18} \mathrm{O}_{4}\right)$. The mass spectrum confirmed the molecular weight as 298.

* Botanical nomenclature according to Copeland ${ }^{1}$.

Acta Chem. Scand. 13 (1959) No. 4 


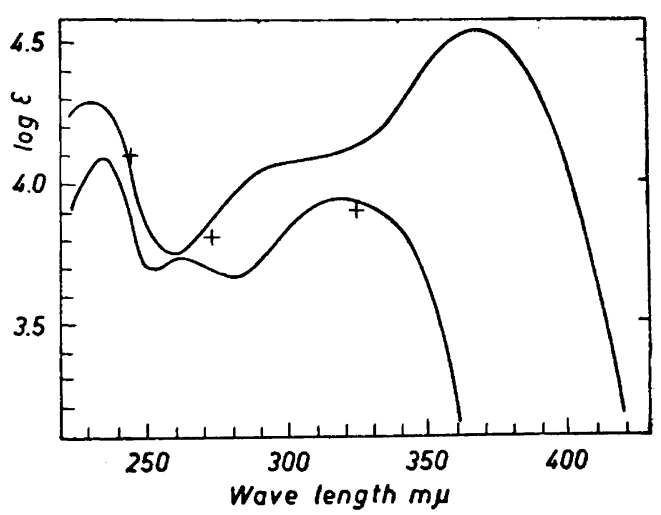

Fig. 1. Ultraviolet spectra of ceroptene (upper curve) and dihydroceroptene (lower curve) in ethanol $(99.5 \%)$. The absorption maxima reported for tasmanon ${ }^{9}$ are indicated by crosses.

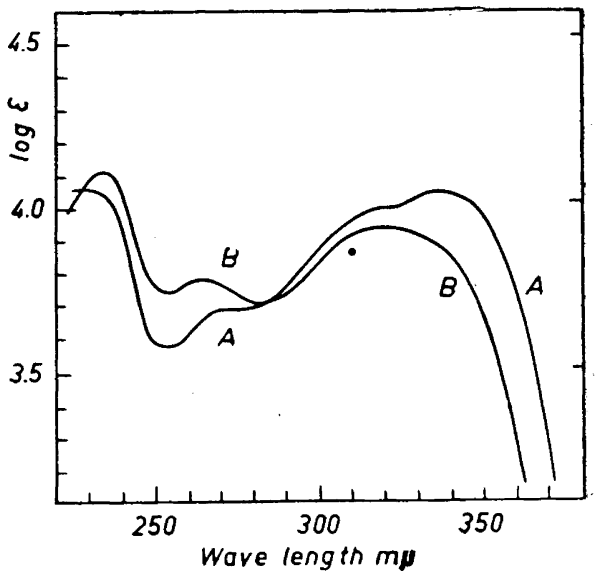

Fig. 2. Ultraviolet spectra of 3-acetylfilicinic acid (A) and O-methyl-3-acetylfilicinic acid (B) in ethanol $(99.5 \%)$.

Ceroptene proved to contain one methoxyl group and one active hydrogen atom; the large consumption of Grignard reagent ( 2.9 mole) in the latter determination indicated the presence of two carbonyl groups also. The C-methyl determination gave 0.4 mole of acetic acid, which suggested the presence of a gem-dimethyl group 4 .

Ceroptene gave a strong, red colour with iron(III) chloride and a chloroform-soluble copper salt (m.p. $253-257^{\circ}$ ). This and the infrared absorption (see below) indicated it to be the chelate enol of a $\beta$-diketone.

Catalytic hydrogenation or reduction with zinc in acetic acid gave colourless dihydroceroptene, m.p. $98-100^{\circ}$.

The presence of a mono-substituted benzene ring, demonstrated by oxidation of ceroptene to benzoic acid, was evident also in the mass spectrum peak at $m / e=77\left(\mathrm{C}_{6} \mathrm{H}_{5}{ }^{+}\right.$, cf. however Ref. $\left.{ }^{5}\right)$. A peak at $m / e=103$ was interpreted as $\mathrm{C}_{6} \mathrm{H}_{5}-\mathrm{CH}=\mathrm{CH}^{+6}$. These peaks were weak in the mass spectrum of dihydroceroptene, which instead gave pronounced peaks at $m / e=91$ and 105, presumably due to $\mathrm{C}_{6} \mathrm{H}_{5}-\mathrm{CH}_{2}{ }^{+}$(rearranged ${ }^{7}$ ) and $\mathrm{C}_{6} \mathrm{H}_{5}-\mathrm{CH}_{2}-\mathrm{CH}_{2}{ }^{+6}$. In the infrared spectrum of ceroptene, bands near $3100,1580,1310$ and $970 \mathrm{~cm}^{-1}$, which did not recur in the spectrum of dihydroceroptene, indicated the presence of a di-substituted, trans-ethylenic double bond conjugated with a benzene ring. The mass spectral and infrared data thus indicate that ceroptene contains a $\mathrm{Ph}-\mathrm{CH}=\mathrm{CH}$ - unit.

Degradation of dihydroceroptene by ozonolysis and subsequent oxidation with alkaline hydrogen peroxide gave hydrocinnamic acid and dimethylmalonic acid confirming the presence of the $\mathrm{C}_{6} \mathrm{C}_{2}$-grouping and also showing the presence of a gem-dimethyl group.

Acta Chem. Scand. 13 (1959) No. 4 
The ultraviolet spectrum of ceroptene (Fig. 1) was rather similar to those of chalcones and other arylidene ketones, but did not give very much further information. The spectrum of dihydroceroptene (Fig. 1) was of considerably greater interest because of the strong band near $320 \mathrm{~m} \mu$. Since the absorption of the non-conjugated benzene ring is negligible this absorption must be due to the remaining part of the molecule. Comparison with known spectra indicated a close resemblance to 3 -acetylfilicinic acid (2-acetyl-6,6-dimethylcyclohexane-1,3,5-trione, I) ${ }^{8}$. The spectrum of this compound (Fig. 2) is the sum of contributions from various tautomers and enolate ions; the absorption above $300 \mathrm{~m} \mu$ appears indeed to be made up of two peaks (325 and $340 \mathrm{~m} \mu$ ). The dihydroceroptene maximum is close to the first peak.

Tasmanone ${ }^{\circ}$, isolated from the essential oil of Eucalyptus risdoni, has been supposed to be 5-methoxy-2-isobutyryl-4,6,6-trimethylcyclohex-4-ene-1,3- dione. Its ultraviolet absorption (maxima indicated in Fig. 1) is similar to that of dihydroceroptene. A comparison with the methyl ether(s) of 3-acetylfilioinic acid appeared however to be desirable for confirmation of the nature of the chromophore.

3-Acetylfilicinic acid was obtained, albeit in small quantity, by alkaline methylation of phloroacetophenone ${ }^{8}$. On treatment with methyl orthocarbonate ${ }^{10}$ it afforded a methyl ether, m.p. 107-109. The ultraviolet spectrum of this O-methyl-3-acetylfilicinic acid (Fig. 2) was similar to that of tasmanone and almost identical with that of dihydroceroptene. There were also striking similarities between the infrared spectra of 0-methyl-3-acetylfilicinic acid and dihydroceroptene.

The alkaline cleavage of ceroptene proceeded very slowly, partly due to the poor solubility of the salt(s) in strong alkali and possibly also due to an unfavourable equilibrium. Prolonged heating with dilute aqueous potassium hydroxide with simultaneous, continuous extraction with toluene gave benzaldehyde and a product identical with the synthetic 0-methyl-3-acetylfilicinic acid $(20 \%)$.

The reverse reaction proceeded smoothly and the condensation of $O$ methyl-3-acetylfilicinic acid with benzaldehyde using piperidine as a catalyst gave ceroptene in good yield.

The evidence shows that ceroptene is the methyl ether of an enol of 2-cinnamoyl-6,6-dimethylcyclohexane-1,3,5-trione (II) but does not give any definite evidence about the position of the methoxyl group.

Of the possible methyl ethers of 3-acetylfilicinic acid only III and V should give conjugate chelated enols. The ultraviolet spectrum gives no direct help towards a choice between them because of lack of reference data. The position of the methoxyl group should however be the same as in tasmanone.

The infrared spectra of 2-acylcyclohexane-1,3-diones show a strong band at $1540-1565 \mathrm{~cm}^{-1}$, which has been ascribed to a carbonyl vibration shifted to low frequency by conjugate chelation accentuated by the symmetry of the $\beta$-triketone system ${ }^{11}$. Ceroptene, dihydroceroptene and O-methyl-3-acetylfilicinic acid all absorb very strongly near $1520 \mathrm{~cm}^{-1}$. This band appears to have a similar origin, the shift to lower frequencies presumably being due to additional conjugation. These compounds appear to be completely enolised since the infrared absorption is independent on the concentration and since 
<smiles>[R]OC1C(=O)C([2H])C(=O)C(C)(C)C1=O</smiles>

$$
\begin{array}{rl}
\text { I } & \mathrm{R}=\mathrm{CH}_{\mathrm{s}}- \\
\mathrm{II} & \mathrm{R}=\mathrm{Ph}-\mathrm{CH}=\mathrm{CH}-
\end{array}
$$<smiles>[R]OC1([R])C(=O)C=CC(C)(OC)C1(C)C</smiles><smiles>[R]C(=O)C1C(=O)C=C(OC)C(C)(C)C1O</smiles><smiles>[R]C1=C2C(=O)C(C)(C)C(OC)=CC2C(O)=C1</smiles>

III $\mathrm{R}=\mathrm{CH}_{3}-$

IV $\mathrm{R}=\mathrm{Ph}-\mathrm{CH}=\mathrm{CH}-$<smiles>[R]OC1C(=O)C(C)(C)C(=O)C=C1OC</smiles>

$\mathrm{V} \quad \mathrm{R}=\mathrm{CH}_{3}-$<smiles>[R]C1C(=O)C(O)C(O)C(C)(C)C1=O</smiles>

VI $\mathrm{R}=\mathrm{Ph}-\mathrm{CH}=\mathrm{CH}-$

the ultraviolet spectra in cyclohexane and in ethanol are fairly similar. This and the very broad and weak $\mathrm{OH}$-absorption near $2000 \mathrm{~cm}^{-1}$ both support the assignment of the chelate carbonyl frequency. Further work on this subject is published elsewhere ${ }^{12}$.

The 2-acylcyclohexane-1,3-diones also show a band near $1660 \mathrm{~cm}^{-1}$ which is ascribed to the non-chelated carbonyl group ${ }^{11}$. This band recurs in the present spectra. The absorption of dihydroceroptene and O-methyl-3-acetylfilicinic acid at 1625 and $1621 \mathrm{~cm}^{-1}$, respectively, is probably due to the enol ether double bond since dimedone methyl ether absorbs at $1620 \mathrm{~cm}^{-1}{ }^{13}$. In ceroptene the peak is observed at $1625 \mathrm{~cm}^{-1}$ and the intensity is increased by the overlapping ethylenic absorption.

Model compounds for prediction of the infrared absorption of 3-methoxy2-acetyl-6,6-dimethylcyclohex-3-ene-1,5-dione (V) are lacking but the striking similarity of the present compounds to the 2-acylcyclohexane-1,3-diones seems to favour structure III (5-methoxy-2-acetyl-6,6-dimethylcyclohex-4-ene-1,3dione) for the synthetic 0 -methyl-3-acetylfilicinic acid. 
Ceroptene is therefore probably 5-methoxy-2-cinnamoyl-6,6-dimethylcyclohex-4-ene-1,3-dione (IV), but structure VI (3-methoxy-2-cinnamoyl-6,6-dimethylcyclohex-3-ene-1,5-dione) is not excluded.

Ceroptene is a somewhat novel addition to the diversified pattern of naturally occurring phloroglucinol derivatives. It embraces the essential features of a $\mathrm{C}_{6} \mathrm{C}_{3} \mathrm{C}_{6}$ compound but is $\mathrm{C}$-methylated to an extent that precludes aromaticity of the phloroglucinoid nucleus and thus is reminiscent of the large group of alkylated 2-acylcyclohexane-1,3-diones and -1,3,5-triones. These have recently been reviewed by Hassall ${ }^{14}$.

The natural order Filicales has given many examples of phloroglucinoid compounds. Dryopterus Filix mas (L.) Schott., of the family Aspidiaceae, which is perhaps the most carefully investigated species, contains a considerable variety of polymethylphloroacylophenones (cf. Ref. ${ }^{14}$ ). Matteucia orientalis (Hooker) Trev. ${ }^{15}$ and Phanerophlebia falcata (L.) Copel. (also known as Cyrtomium falcatum $)^{16}$ belong to the same family. They have been found to contain matteucinol (5,7-dihydroxy-4'-methoxy-6,8-dimethylflavanone), desmethoxy-

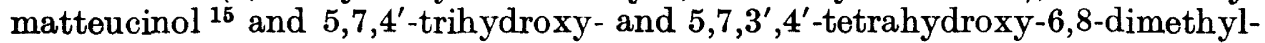
flavanone ${ }^{16}$.

Although C-alkylated phloroglucinol derivatives are also known from higher plants the wide variety of compounds of this type found in the natural order Filicales appears to offer particular scope for comparative biogenetic studies and for biochemical investigations on the formation and transformations of phloroglucinoid compounds.

It is tempting to speculate on the possible physiological significance of the ceroptene coating of $P$. triangularis. $\beta$-Triketones are known to exhibit antibacterial and sometimes insecticidal activity and in some cases have shown an unusual hypermetabolic activity similar to that of 2,4-dinitrophenol ${ }^{17}$. It is interesting to note that the young shoots of the "ceraceous ferns" are almost covered with pigment but the coating of the full-grown plants is confined to the dorsal surfaces of the fronds. Possibly the ceroptene coating acts as a protection duing the early growth of the fern.

\section{EXPERIMENTAL}

Melting points were determined on a Kofler block. The infrared spectra were recorded on a Perkin Elmer No. 21 instrument fitted with a sodium chloride prism, and the ultraviolet spectra were measured on a Beckman DU instrument. The microanalyses were done in the laboratory of Dr. A. Bernhardt, Mülheim, Germany.

Isolation. Fronds and stems of Pityrogramma triangularis, collected in California during summer 1957 (180 g), were washed briefly with ether until the extract was almost colourless. The ether solution was filtered and evaporated giving a semi-crystalline mass, m. p. $119-135^{\circ}(7.1 \mathrm{~g})$. Further extraction with ether gave a greenish, waxy material $(1.8 \mathrm{~g})$, which was not investigated. The first extract was partitioned between dimethyl sulphoxide and light petroleum (b. p. $40-60^{\circ}$ ). The latter phase on evaporation gave a yellowish wax, $\mathrm{m}$. p. $55-68^{\circ}(1.5 \mathrm{~g})$. The dimethyl sulphoxide solution was poured into water and the mixture was exhaustively extracted with ether. The ether solution was evaporated to a small volume, washed with water and extracted successively with sodium hydrogen carbonate (sat.), sodium carbonate (sat.) and sodium hydroxide (0.5 M) solutions. On extraction with carbonate the ether solution took on a peculiar greenish colour, probably due to trace metal chelation. If extracted with stronger sodium hydroxide solutions the sodium salt of ceroptene precipitated as an oil. 
This fractionation gave: 1) Neutral material, $0.7 \mathrm{~g}$; 2) Hydrogen carbonate soluble fraction, $0.02 \mathrm{~g}$; 3) Carbonate soluble fraction, $0.3 \mathrm{~g}$ and 4) Alkali-soluble fraction, $3.9 \mathrm{~g}$. Fractions $1-3$ have not been investigated. Fraction 4 was a crystalline, yellow mass and on recrystallisation from methanol gave ceroptene as lemon-coloured prisms and plates, m. p. $137-140^{\circ}(3.0 \mathrm{~g})$. Further recrystallisation and sublimation $\left(130^{\circ}, 0.05 \mathrm{~mm}\right)$ did not improve the m. p. In chloroform solution ceroptene was optically inactive.

Analytical data. Found: $\mathrm{C} 72.3,72.2 ; \mathrm{H} \mathrm{6.4,6.0;} \mathrm{O} 21.0 ; \mathrm{CH}_{3} \mathrm{O}$ 13.8; active $\mathrm{H}$ 0.44; $\mathrm{CH}_{3}$-(C) 2.1. Calc. for $\mathrm{C}_{18} \mathrm{H}_{18} \mathrm{O}_{4}$ : C 72.5; $\mathrm{H}$ 6.1; $\mathrm{O} 21.5 ; \mathrm{CH}_{3} \mathrm{O}$ (one) 10.4; active $\mathrm{H}$ (one) $0.34 ; \mathrm{CH}_{3}$-(C) (one) $5.0 ; \mathrm{M} 298.3$.

C-Methylated phloroacetophenones are notorious in giving varying methoxyl analyses ${ }^{8}$.

Infrared spectrum (measured in carbon tetrachloride solution with the exception of the italicised figures, which denote absorptions measured on a potassium bromide disc in regions of strong solvent absorption): $3120 \mathrm{w}, 3080 \mathrm{w}, 3040 \mathrm{w}, 3000 \mathrm{~m}, 2960 \mathrm{~m}, 2900$ w, 2860 w, 1655 vs, 1625 vs, 1580 s, 1515 vs, 1475 vs, 1450 vs, l 440 vs, 1385 vs, 1355 $\mathrm{m}, 1335 \mathrm{~m}, 1300 \mathrm{~m}, 1286 \mathrm{w}, 1232 \mathrm{vs}, 1200 \mathrm{~m}, 1165 \mathrm{~s}, 1075 \mathrm{w}, 1040 \mathrm{w}, 995 \mathrm{~m}, 985 \mathrm{~m}$, $979 \mathrm{~m}, 875 \mathrm{w}, 870 \mathrm{~m}, 838 \mathrm{w}, 823 \mathrm{w}, 792 \mathrm{w}, 760 \mathrm{~m}, 728 \mathrm{w}$ and $700 \mathrm{~cm}^{-1} \mathrm{w}$. In the region $3100-1900 \mathrm{~cm}^{-1}$ there was a very weak and broad absorption.

The mass spectrum was recorded by Ing. R. Ryhage, Laboratory for Mass Spectrometry, Karolinska Institutet, Stockholm, with an apparatus equipped with an all-glass heated inlet system ${ }^{18}$. This system gave a fairly large parent peak but preliminary attempts to use a conventional metal inlet system gave extensive cracking and a very low peak for the unfragmented molecule-ion. Only major peaks and peaks relevant to the discussion are given. The figures in brackets are intensities given as per cent of the $m / e=221$ pesk. $299(25), 298(96), 297(38), 283(37), 280(19), 227(47), 222(21), 221$ (100), 195 (8), 131 (81), $126(78), 125(49), 115(16), 111(46), 105(6), 104(14), 103(19)$, 102 (14), 95 (11), $91(8), 83$ (10) and 77 (46).

The copper salt was prepared in aqueous methanol and was recrystallised from chloroform-cyclohexane to give bronze-glistening plates, m. p. 253-257 . (Found: C 64.2; $\mathrm{H}$ 5.1; residue 11.0. Calc. for $\mathrm{C}_{36} \mathrm{H}_{34} \mathrm{CuO}_{8}$ : C 65.9; $\mathrm{H}$ 5.2; $\mathrm{CuO}$ 12.0.) The salt could not be sublimed.

Ceroptene gave a strong red colour with iron(III) chloride in methanol. No reaction was obtained with diazotised benzidine even after addition of sodium carbonate or with 2,4-dinitrophenylhydrazine.

Hydrogenation. Ceroptene $(0.30 \mathrm{~g})$ in absolute ethanol $(20 \mathrm{ml})$ on hydrogenation over palladised charcoal $(0.08 \mathrm{~g}, 10 \%)$ absorbed one mole of hydrogen in one hour. After filtration, evaporation and recrystallisation from methanol dihydroceroptene $(0.21 \mathrm{~g})$ was obtained as prisms and was finally purified by sublimation, m. p. 98-100. (Found: C 72.7; $\mathrm{H}$ 6.7; $\mathrm{CH}_{3} \mathrm{O}$ 10.4. Calc. for $\mathrm{C}_{18} \mathrm{H}_{20} \mathrm{O}_{4}$ : $\mathrm{C} 72.0 ; \mathrm{H}$ 6.7; $\mathrm{CH}_{3} \mathrm{O}$ 10.3.) Infrared spectrum (in carbon tetrachloride solution and in a potassium bromide disc): $3070 \mathrm{w}, 3020$ $\mathrm{m}, 2980 \mathrm{~m}, 2920 \mathrm{w}, 1665 \mathrm{vs}, 1625 \mathrm{vs}, 1525 \mathrm{vs}, 1495 \mathrm{vs}, 1480 \mathrm{vs}, 1462 \mathrm{vs}, 1390 \mathrm{vs}$, $1360 \mathrm{~s}, 1285 \mathrm{~m}, 1270 \mathrm{w}, 1230 \mathrm{vs}, 1200 \mathrm{~s}, 1165 \mathrm{vs}, 1082 \mathrm{~m}, 1060 \mathrm{~m}, 1035 \mathrm{w}, 1000 \mathrm{~s}$, $965 \mathrm{~m}, 845 \mathrm{~s}, 835 \mathrm{~s}, 810 \mathrm{w}, 750 \mathrm{~s}$, and $695 \mathrm{~cm}^{-1} \mathrm{~m}$.

Mass spectrum: 301 (21), 300 (100), 286 (16), 285 (91), 282 (13), 267 (15), 196 (11), 195 (35), $181(17,169(16), 168(98), 153(11), 126(22), 125(20), 111(16), 105(13), 104$ (6), $103(6), 95(7), 91(28)$ and $77(6)$.

When treated with copper (II) acetate in aqueous methanol dihydroceroptene gave a greenish blue copper salt, m. p. ca. $200^{\circ}$, which was not, however, obtained in a state of purity.

Oxidation. Ceroptene was oxidised with potassium permanganate in pyridine-aqueous alkali to give benzoic acid $(0.7 \mathrm{~mole}), \mathrm{m}$. p. and mixed m. p. $120-123^{\circ}$.

Ozonolysis of dihydroceroptene. Dihydroceroptene $(0.16 \mathrm{~g})$ in methylene chloride $(20 \mathrm{ml})$ was treated with ozone at $-78^{\circ}$ for one hour. The solvent was removed under reduced pressure below room temperature and the residue was oxidised with hydrogen peroxide $(30 \%, 1 \mathrm{ml})$ in aqueous alkali $(2 \mathrm{M}, 5 \mathrm{ml})$ on the water bath for $0.5 \mathrm{~h}$. The cooled solution was acidified and extracted with ether and the extract was evaporated at room temperature to give an oily mixture. Extraction with cold cyclohexane dissolved part of it leaving a colourless, crystalline material $\left(28 \mathrm{mg}\right.$ ), which melted at $190^{\circ}$ with effervescence and then gave an odour of $i$ sobutyric acid. Mixed $\mathrm{m}$. $\mathrm{p}$. with dimethylmalonic acid gave no depression and the infrared spectra were identical. Evaporation of the cyclohexane solution gave a low-melting solid, which was recrystallised from dilute hydro-

Acta Chem. Scand. 13 (1959) No. 4 
chloric acid to give a product with an unsharp melting point $\left(38-48^{\circ}, 30 \mathrm{mg}\right)$, the infrared spectrum of which was identical with that of hydrocinnamic acid.

Alkaline cleavage of ceroptene. Ceroptene $(50 \mathrm{mg})$, was dissolved in aqueous potassium hydroxide (1 M, $10 \mathrm{ml}$ ). The solution was kept on the water bath under continuous extraction with toluene. Samples were withdrawn at intervals and examined by paper chromatography in the system tetralin, acetic acid, water $(10: 10: 1)^{10}$. The spots were detected by spraying with iron (III) chloride in methanol. After $50 \mathrm{~h}$ the ceroptene $\left(R_{F} 0.7\right)$ had disappeared and the main product had $R_{F} 0.6$. There was also a faint spot at $R_{F} 0.3$, probably 3 -acetyl-filicinic acid. The aqueous solution was acidified and extracted with ether and the ether extract after drying was evar,orated to give a solid, m. p. 85$100^{\circ}(23 \mathrm{mg})$. Sublimation gave colourless needles, $\mathrm{m} ; .90-103^{\circ}(6 \mathrm{mg})$. The ultraviolet and infrared $(\mathrm{KBr})$ spectra were identical with those of the synthetic methyl ether of 3-acetylfilicinic acid described below.

The toluene solution was heated with an excess of 2,4-dinitrophenylhydrazine on the water bath for $2 \mathrm{~h}$ and was then extracted with dilute hydrochloric acid and evaporated to give an orange solid which was triturated with ethanol to give benzaldehyde 2,4dinitrophenylhydrazone, m. p. and mixed m.p. $236-239^{\circ}(8 \mathrm{mg})$.

Methylation of 3-acetylfilicinic acid. C-Methylation of phloroacetophenone according to Riedl and Risse ${ }^{8}$ gave 3-acetylfilicinic acid in $5 \%$ yield, m. p. 178-182 . (Reported $^{\circ}$ yield $4 \%$ m. p. $174-176^{\circ}$.) The ultraviolet spectrum agreed with that given by these authors and a portion boiled with dilute hydrochloric acid gave filicinic acid, m. p. 216 $224^{\circ}$ (decomp.). (Reported m. p. 214-216 ${ }^{\circ}$.)

3-Acetylfilicinic acid $(63 \mathrm{mg})$ and methyl ortocarbonate ${ }^{20}(0.2 \mathrm{ml})$ were heated on the water bath for $3 \mathrm{~h}$. Light petroleum $(2 \mathrm{ml})$ was added and after cooling the mixture deposited needles, m. p. $97-105^{\circ}(47 \mathrm{mg})$. Sublimation and recrystallisation from light petroleum gave the methyl ether as needles, m. p. 107-109 ${ }^{\circ}$. (Found: C 63.2; H 6.8; $\mathrm{CH}_{8} \mathrm{O}$ 14.6. Calc. for $\mathrm{C}_{11} \mathrm{H}_{14} \mathrm{O}_{4}$ : $\mathrm{C} 62.8 ; \mathrm{H} \mathrm{6.7;} \mathrm{CH}_{3} \mathrm{O}$ 14.7.)

Infrared spectrum (in carbon tetrachloride): $3080 \mathrm{w}, 2995 \mathrm{~m}, 2950 \mathrm{~m}, 2860 \mathrm{w}$, 1660 vs, 1621 vs, 1525 vs, 1477 vs, 1455 vs, $1385 \mathrm{~s}, 1350 \mathrm{~m}, 1260 \mathrm{w}, 1230$ vs, $1200 \mathrm{~m}$, 1167 vs, $1081 \mathrm{~m}, 1030 \mathrm{w}, 1000 \mathrm{~m}, 962 \mathrm{~m}, 845 \mathrm{w}, 740 \mathrm{~m}, 676 \mathrm{w}$.

The copper salt was obtained as blue prisms from aqueous methanol, m. p. ca. $240^{\circ}$ (some decomposition from $200^{\circ}$ ). It was not obtained in a state of purity.

Synthesis of ceroptene. Synthetic O-methyl-3-acetylfilicinic acid (11 mg), benzaldehyde $(50 \mathrm{mg}$ ) and piperidine $(5 \mathrm{mg}$ ) were heated on the water bath for $0.5 \mathrm{~h}$ and then methanol $(1 \mathrm{ml})$ was added. On standing ceroptene separated as prisms, m. p. and mixed m. $\mathrm{p}$. $138-140^{\circ}(9 \mathrm{mg})$. The infrared spectrum was identical with that of the natural product (KBr).

Acknowledgements. The present investigation was proposed by Professor H. Erdtman, who collected the initial fern material. For this and for his encouraging interest in the work I wish to express my sincere gratitude. Thanks are also due to Dr. K. Folkers, Rahway, Dr. R. W. Miller, San Francisco, Dr:s Alice and Rolla Tryon, Los Angeles and Professor E. Werdermann, Berlin-Dahlem for generous gifts of material.

I also wish to thank Ing. R. Ryhage for the determination of the mass spectra and discussions on the interpretation, Miss Gurli Hammarberg for skilful assistance in the measurements of infrared and ultraviolet spectra and Dr. B. R. Thomas for linguistic comments.

\section{REFERENCES}

1. Copeland, E. B. Genera Filicum, Waltham, Mass. 1947.

2. Blasdale, W. C. J. Am. Chem. Soc. 25 (1903) 1141.

3. Zopf, W. Ber. deut. botan. Ges. 24 (1906) 264.

4. Roth, H. in Müller, E. (Ed.) Methaden der organischen Chemie (Houben-Weyl), Band 2, Thieme, Stuttgart 1953, p. 273.

5. Meyerson, S. and Rylander, P. N. J. Am. Chem. Soc. 79 (1957) 1058.

6. Am. Petrol. Inst. Research Project 44, "Catalog of Mass Spectral Data", Carnegie Inst. of Technology, Pittsburgh, Pa., 1947-1956, Nos. 359, 177.

7. Rylander, P. N., Meyerson, S. and Grubb, H. M. J. Am. Chem. Soc. 79 (1957) 842.

Acta Chem. Scand. 13 (1959) No. 4 
8. Riedl, W. and Risse, K. H. Ann. 585 (1954) 209.

9. Birch, A. J. and Elliott, P. Austr. J. Chem. 9 (1956) 95.

10. Smith, B. Acta Chem. Scand. 10 (1956) 1006.

11. Chan, W. R. and Hassall, C. H. J. Chem. Soc. 19563495.

12. Forsén, S. and Nilsson, M. Acta Chem. Scand. 13 (1959) In press.

13. Heymann, H., Bhatnagar, S. S. and Fieser, L. F. J. Am. Chem. Soc. 76 (1954) 3689.

14. Hassall, C. H. Progr. in Org. Chem. 4 (1958) 115.

15. Fujise, S. Sci. Papers Inst. Phys. Chem. Research (Tokyo) 11 (1929) 111, after Chem. Zentr. 1930 I 236.

16. Kishimoto, Y. Pharm Bull (Tokyo) 4 (1956) 24.

17. Söderberg, U. and Wachtmeister, C. A. J. Pharmacol. Exptl. Therap. 117 (1956) 298.

18. Ryhage, R. Arkiv Kemi. 13 (1959) 475.

19. Brockmann, H. and Müller, W. Unpublished results communicated by H. Vorbrüggen.

20. Smith, B. and Delin, S. Svensk Kem. Tidskr. 65 (1953) 10.

Received January 12, 1959. 